\title{
Muralf
}

INTERNACIONAL

\section{As relações de paz e guerra entre Peru e Equador no contexto do complexo de segurança regional The relations of peace and war between Peru and Ecuador in the context of regional security complex SAMUEL CORREA DUARTE ${ }^{1}$}

Resumo: O presente estudo procura analisar os acontecimentos centrais relativos à Guerra do Cenepa ocorrida em 1995 na fronteira entre Peru e Equador, situando a mesma no contexto da segurança regional do complexo americano. Argumentamos que a Guerra do Cenepa produziu três resultados básicos: apontou para a existência de uma balança de poder entre os dois países; não gerou nenhuma alteração substancial no conteúdo do tratado firmado anteriormente sobre a fronteira na base do Rio Cenepa; nem tampouco implicou em transferência de território. Então, como podemos explicar a dinâmica do conflito entre Peru e Equador? A tese central da análise que será aqui empreendida é que, em primeiro lugar, um padrão recorrente de hostilidades favorece um comportamento ofensivo e, em segundo lugar, a certeza sobre a balança de poder favorece as negociações. Como tese subjacente defendemos que a prevalência da hegemonia norte-americana contribuiu para o desenlace do conflito.

Palavras-chave: segurança regional; fronteira; conflito.
Recebido em:

26 de Julho de 2016

Received on:

July 26, 2016

Aceito em:

07 de Agosto de 2017

Accepted on:

August 07, 2017

DOI: 10.12957/rmi.2016.24824

Abstract: The present study aims to analyze the central events related to the Cenepa War that occurred in 1995 on the border between Peru and Ecuador, into regional security of the American complex. We argue that the Cenepa War produced three basic results: pointed to the existence of a balance of power between the two countries; did not generate any substantial change in the content of the previously signed treaty on the border at the base of the Rio Cenepa; nor did it entail transfer of territory. How can we explain the dynamics of the conflict between Peru and Ecuador? Central thesis of the analysis that will be undertaken here is that, first, a recurrent pattern of hostility favors offensive behavior, and secondly, certainty about the balance of power favors negotiations. As an underlying thesis, we argue that the prevalence of US hegemony contributed to the outcome of the conflict.

Keywords: regional security; border; conflict.

${ }^{1}$ Mestre em Ciência Política e Mestre em Planejamento e Desenvolvimento Territorial. Professor Assistente do curso de Pedagogia da Universidade Federal do Tocantins. Endereço para correspondência: Universidade Federal do Tocantins (UFT), Campus Arraias, Avenida Juraildes de Sena Abreu, s/n. Setor Buritizinho, Arraias - TO, CEP 77330-000. E-mail: samuelcorrea@uft.edu.br 
$\mathrm{O}$ presente estudo visa identificar e analisar um caso de dinâmica regional de segurança, no qual estão envolvidos tanto fatores históricos pertinentes ao contexto específico dos países envolvidos quanto fatores estruturais pertinentes ao sistema político internacional como um todo. Dito de maneira mais explícita, nos interessa saber qual é o impacto da fricção geopolítica para o dinâmica das relações entre povos vizinhos e como um conflito evolui no ambiente de incerteza da anarquia estrutural que caracteriza as relações interestatais. Questiona-se em que medida a evolução de tais conflitos pode estar associada com o padrão de relacionamento estabelecido entre os Estados e a respectiva distribuição de poder. A importância desse propósito é permitir identificar, também, as condições nas quais se pode produzir a paz pela acomodação das tensões e incertezas que afetam uma dada dinâmica de segurança regional.

O estudo em tela tem como objeto básico as relações de paz e guerra entre Peru e Equador. A evolução das relações entre esses dois Estados remonta ao período colonial e ao processo de independência de ambos no século XIX, coexistindo com o processo de formação das respectivas identidades nacionais e chegando até fins do século XX. Para realizar a análise do objeto supracitado iremos recorrer ao conceito de complexo regional de segurança.

De acordo com Waltz (1959, pp.1-15) uma das questões mais importante da temática da segurança internacional é saber se existem meios de reduzir a incidência da guerra, de aumentar as chances de uma paz prolongada. Parece correto pensar que o caminho para a paz passa por uma melhor compreensão das causas da guerra. Nesse sentido, onde pode ser encontrada a causa da guerra: no homem enquanto ser social, na estrutura dos Estados individuais ou no sistema de Estados? Segundo aquele autor a resposta é que os três níveis são importantes na compreensão da guerra como fenômeno social e político. Devemos levar em conta que compreender as consequências de qualquer um dos níveis de análise requer entendê-lo em si mesmo e também em relação aos demais, de modo a obtermos uma visão integrada das causas e dinâmica de um dado conflito internacional. Isto porque toda prescrição para uma grande paz no mundo está relacionada a alguma combinação destas três fontes de discórdia mencionadas acima.

O método que será empregado aqui para analisar a relação de segurança internacional entre Peru e Equador, será o seguinte: tratar a ideia de complexo de 


\section{Muralf}

INTERNACIONAL

segurança como recurso analítico para compreensão das interações em foco e a seguir proceder o escrutínio das relações bilaterais. No nível regional iremos destacar o papel do Brasil nas negociações de paz e no nível macro a presença e atuação dos Estados Unidos. Como aspectos auxiliares na análise estarão presentes elementos relacionados com a dinâmica própria de cada nível (social, estatal e interestatal) e suas conexões, a estabilidade da ordem política e social de cada país, o padrão de relacionamento mútuo e a relação de poder entre os países envolvidos, bem como a influência da dinâmica regional e global na produção da guerra e da paz.

Adrian Bonilla (2002, p.12) entende que os temas de ordem internacional e doméstico são interligados, especialmente em caso de conflitos e resolução dos mesmos. Nesse sentido, de acordo com Buzan e Little (1993, p.62), a coesão sociopolítica indica que os Estados podem ser diferenciados em termos de um quadro de referência que vai dos Estados fortes, ou seja, aqueles com uma relação entre Estado e sociedade bem integrada, até Estado fracos, dotados de relação frágil e instável. Isso é importante porque os processos políticos internos de Estados fracos estão vinculados à natureza da
Mural Internacional

V. 7 | N. 2

JUL-DEZ 2016

inserção dos mesmos na ordem internacional.

Os combates ocorridos entre Peru e Equador em 1995 foram limitados em termos de espaço, pois se restringiram a uma pequena zona de fronteira sob disputa; também foram limitados em termos de perdas e danos de ambos os lados; bem como suscitaram o emprego de forças e logística reduzidas em combate efetivo, por fim, foram limitados em duração, tendo ocorrido num período de apenas algumas semanas (Núñez 2002, pp.2-3).

Mas nem por isso tais combates deixaram de configurar uma guerra, tendo em vista $o$ fato de ter exemplificado uma tentativa de ambos os lados envolvidos em compelir o outro a aceitar diretivas pela força, valendo também destacar o nível de mobilização das respectivas forças armadas, o risco de escalada armamentista e a relevância do tema em disputa para a segurança nacional, especialmente devido ao histórico de rivalidade. Quanto a esse último tópico, destacamos que o conflito de 1995 deve ser visto dentro do quadro mais amplo e complexo das conturbadas relações estabelecidas entre Peru e Equador desde os primeiros tempos destes dois países como nações independentes (Nogueira e Herz 2002, p.47). 
Nosso primeiro ponto a ser analisado é a ideia de complexo de segurança e sua aplicabilidade ao caso latino-americano. São vários os fatores que informam as relações de amizade e inimizade entre os povos. Dentre eles podemos identificar as disputas fronteiriças, os preconceitos étnicos, os alinhamentos ideológicos, as relações históricas etc. O resultado de uma dinâmica regional de relações internacionais é a constituição de um 'complexo de segurança', definido como um conjunto de Estados cuja segurança está vinculada pela proximidade geográfica, de modo que a segurança de um não pode ser plenamente acessada sem pensar a segurança do(s) vizinho(s). Isto porque, como já foi dito, as ameaças ganham potência em contextos de curta distância, de modo que as relações entre vizinhos têm grande importância na agenda de segurança.

Assim como uma balança de poder, um complexo de segurança pode existir e operar sem que os Estados envolvidos o reconheçam propriamente, mas tão somente as linhas gerais de amizade e inimizade, bem como as ameaças regionais, sem considerar a existência de um padrão relacional regional. É claro que se um Estado reconhecer a dinâmica regional da qual faz parte, estará mais apto a agir, estrategicamente, em relação a ela a seu próprio favor. $\mathrm{O}$ fato é que a interdependência regional gera padrões de relacionamento e segurança específicos.

Tratando do caso da América Latina, devemos ter em mente que as origens do complexo de segurança latinoamericano remontam ao processo de descolonização e ao desenvolvimento de instituições estatais e identidades nacionais na região, dentro dos moldes do Estado Nacional europeu. Esse desenvolvimento apenas se cristalizou propriamente em complexo de segurança, após as guerras de independência. A América Latina, embora sofra alguma sobreposição (overlay) em matéria de segurança devido à presença dos Estados Unidos, especialmente manifesta através da OEA (Organização dos Estados Americanos), atualmente apresenta sua própria dinâmica de segurança comunitária, exemplificada pelo Tratado de Tlatelolco (Latin American Nuclear Weapon Free Zone) que baniu o uso de armas nucleares na região. É claro que existem tensões entre os Estados Unidos e a comunidade latina, como evidenciam o suporte norte-americanos aos regimes militares instalados na região ao longo do século $\mathrm{XX}$ como parte de um programa de defesa contra a expansão socialista. 


\section{Muralf}

INTERNACIONAL

Segundo Ferraz e Hauser (2002, pp.2627), foi na $29^{\text {a }}$ Assembleia Geral da Organização dos Estados Americanos (OEA), ocorrida em julho de 1999, que o delegado dos EUA levou a público a sugestão de que grupos de países vizinhos ou vinculados via mercado e política, deveriam ter ao seu dispor a possibilidade de interferir em conflitos internos de outra nação da região americana, sem ter que solicitar a aprovação prévia da Assembleia. Obviamente, a comunidade latina traduziu esta proposta como um indicativo de que o governo da Casa Branca pretendia exercer um controle mais ativo sobre os países da região.

O fato é que a ausência de ameaças ostensivas de outras potências contra a segurança da América do Norte permite ao governo da Casa Branca uma grande amplitude na escolha de sua política externa. Como poder hegemônico, os Estados Unidos podem escolher onde, quando e como agir na arena internacional com base em seus próprios interesses.

Uma das questões postas por Buzan e Waever (2003, pp.313-314) é que o desenvolvimento histórico regional indica a existência de vários casos de conflitos efetivos ou latentes na comunidade latina. Do ponto de vista histórico e regional, de um total de 23
Mural Internacional

V. 7 | N. 2

JUL-DEZ 2016 guerras com participação de países latinos, 17 delas envolveram apenas países do continente americano. Nove ocorreram no século XIX e oito no século XX. Estados surgiram da fricção interestatal no período pós-colonial. O Uruguai surgiu da mediação britânica realizada na guerra entre Brasil e Argentina de 1825. O Panamá deve sua origem em 1903, em parte, devido a uma guerra civil na Colômbia, num processo que teve ativa participação dos EUA. A antiga Grande Colômbia se dividiu em três Estados sendo que um deles, o Equador, enfrentou conflitos recorrentes para manter sua unidade.

As guerras também alteraram a distribuição de poder regional. Se a América Central houvesse conseguido se manter unida, fatalmente teria se constituído num ator de extrema relevância no que tange à dinâmica de segurança regional, porém as guerras não permitiram que isso ocorresse. Mas o grande impacto em termos de poder veio com as Guerras da Confederação entre Peru e Bolívia (1836-1839) e a da Tríplice Aliança (1836-39). Essas guerras terminaram por evitar a criação de Estados mais poderosos na região pelo rearranjo da distribuição de poder.

De acordo com Espinosa (1999, p.113) diversos conflitos sul-americanos correlatos ao de Cenepa envolvendo 
Peru e Equador, como Peru-Argentina, Bolívia-Paraguai,

Chile-Argentina, foram resultado do processo de constituição do Estado-Nação no período pós-colonial no século XIX com repercussões no século XX. Nesse processo de formação do Estado-Nação o poder estatal se institucionalizou e lançou as bases da identidade nacional tomando como referência o território.

Diante disso, pode-se questionar porque os conflitos derivados do processo colonial que não eclodiram em guerra de larga escala nem geraram uma corrida armamentista em sentido amplo na região. Uma explicação aventada é que o Brasil atua como um estabilizador hegemônico que prefere a via diplomática à lógica bélica, associando seus interesses regionais à manutenção da estabilidade regional na qual se torna vital evitar o acirramento das tensões latentes.

Cabe ressaltar que a maioria dos conflitos já ocorridos na região estavam vinculados a disputas territoriais. A expansão da fronteira agrícola brasileira em direção à região amazônica pode, futuramente, romper com o isolamento dos centros de poder e criar mais espaços de fricção e consequentes ameaças mútuas advindas de interações geopolíticas mais estreitas entre os países da Costa Oeste e o Brasil, ou talvez o fim da Guerra Fria e a relativa desmobilização da atenção norte americana sobre a região com o tempo crie espaços para uma disputa mais aberta pela hegemonia regional, bem como ações de contestação das fronteiras.

Fronteira imprecisas ou sob judice são causa comum de atritos em regiões que foram colônias. Por um lado, é significativo que uma região como a América Latina, com um largo histórico de regimes militares, tenha recorrido tão pouco às armas para resolver disputas internacionais. Por outro lado, a longa duração dos conflitos fronteiriços também pode estar ligada à existência de recursos naturais ou acessos logísticos de relevância. Além disso esses conflitos podem ser recidivos tendo em vista um histórico de atritos. Em vista desses fatores, que desde a Guerra do Cenepa de 1995 tem-se tornado corrente o recurso à arbitragem externa para dirimir contendas (Paterson e Flynn 2013, pp.6-8).

Complexos de segurança também podem ser vistos como estruturas, permitindo que se identifique sua dinâmica e processos de mudança. Registre-se aqui que os dois componentes básicos da estrutura de um complexo de segurança são os padrões de amizade e inimizade, e também a 


\section{Muralf}

INTERNACIONAL

distribuição de poder entre os Estados. Uma mudança em qualquer um destes fatores significa, também, mudanças na estrutura do subsistema regional. Uma vez que o complexo de segurança possui estrutura, então é possível analisar os resultados dos efeitos estruturais sobre os atores envolvidos e também os processos estruturais de mudança (Buzan 1991, p.209).

A distribuição de poder em um complexo de segurança informa os alinhamentos possíveis, enquanto os padrões de amizade e inimizade condicionam as relações dentro do complexo. Mudanças nos padrões de relacionamento podem ocorrer porque um conflito ou disputa foi resolvido ou porque novos confrontos têm se desenvolvido. Em geral, o impacto de uma mudança de poder ou de hostilidade pode ser identificado sob quatro formas diferentes: manutenção de status quo, transformação interna, transformação externa e overlay. Trataremos aqui em particular desse último tipo por entender que ele se aplica com maior propriedade ao caso em tela.

A noção de overlay indica a presença da ação de um ou mais poderes externos diretamente sobre um complexo de segurança regional, produzindo o efeito de constranger a dinâmica local de
Mural Internacional

V. 7 | N. 2

JUL-DEZ 2016 segurança. Em geral, o overlay toma forma de uma aliança desigual, na qual um poder menor se compromete com as posições de um poder maior. Assim, a dinâmica de segurança local é subordinada à orientação do poder dominante, que destaca forças militares e aparatos de segurança para se posicionarem na região. Os Estados locais se resignam porque temem aos poderes externos ou a uma dinâmica regional desfavorável. Diante disso, podemos dizer que o overlay só é possível se existir um poder externo com uma capacidade militar superior e massiva, capaz de ser aplicado localmente no complexo de segurança em questão. De igual modo para sua ocorrência deve haver vontade política por parte dos Estados locais em dar apoio logístico, econômico e estratégico a uma força externa. Além, é claro, do interesse do próprio poder externo.

Como podemos depreender da análise até aqui, nosso argumento é que o caso do complexo de segurança latino americano caracteriza um tipo especial, pois combina traços de overlay, através da presença norte-americana, com uma dinâmica própria informada pelas relações de amizade e inimizade entre os Estados; estão presentes a recorrência de disputas territoriais derivadas dos processos de acomodação pós-colonial, a predominância dos Estados Unidos, 
mas também uma disputa pela influência regional envolvendo especialmente o Brasil, a Argentina, o México e, porque não dizer, em menor grau, também o Chile.

Devemos observar que a América do Sul passou por uma transição democrática nos idos dos anos 1980 e 1990, com profundas alterações na visão política dos Estados constituintes dessa região. As políticas macroeconômicas, sociais e desenvolvimentistas colocadas em curso demandavam estabilidade política para surtirem o efeito esperado. No que tange à atuação da chancelaria brasileira, tem-se notado um recorrente cuidado para liderar a região de forma compartilhada, sem caracterizar uma hegemonia unilateral sob risco de desestabilizar as relações circunvizinhas (Ludwig 2015, pp.20-21).

O fato de que as tensões existentes na América do Sul não ganhem uma expressão militarizada não significa que seja uma área pacificada ou livre de ocorrências bélicas. A região foi marcada durante quase todo o século XX pela disputa regional entre Brasil e Argentina. Mas no pós-Guerra fria o centro gravitacional da instabilidade regional migrou do Cone Sul para a região Andina (Teixeira Júnior 2012, pp.194-195).
Em geral, o principal fator que define um complexo de segurança é um alto nível de medo e ameaça mútua entre Estados. Um complexo regional pode ser identificado pela retórica de segurança mútua entre Estados, pelo investimento militar em zonas fronteiriças e o histórico de conflitos. Pode ser que um complexo de segurança seja sublinhado por questões étnicas e culturais, definindo relações de amizade e inimizade.

Todos estes fatores estão presentes no contexto latino-americano e podem ser exemplificados com o caso das relações de paz e guerra envolvendo Peru e Equador. As relações de suspeita e a retórica de prevenção armada permeiam as relações bilaterais desde as primeiras décadas que se seguiram à independência de ambas as nações após os tempos coloniais, com a ativa contribuição para a inimizade de fatores provenientes da influência histórica, política e social. Enquanto isto, o investimento militar na fronteira tem sido uma constante, bem como o histórico de conflitos, com a ocorrência de, pelo menos, três enfrentamentos armados relevantes.

Por ocasião da Guerra do Cenepa, tanto Equador quanto Peru eram nações com baixa integração interna e em processo de transição para a democracia. A 


\section{Muralf}

INTERNACIONAL

fragilidade das instituições políticas e econômicas tinham como contrapeso um protagonismo militar no Equador. De outra sorte, no Peru assistia-se a uma tensão entre civis e militares tendo em vista o tratamento dispensado por Fujimori a estes últimos (Marcella 1995, pp.13-14).

Assim, ao pensar o problema da segurança na região andina, e a bem dizer, de toda a América Latina, um ponto a ser destacado é que a política externa norte-americana é um importante fator a influenciar a agenda local, tendo em vista a enorme assimetria de poder, o que faz com que os países andinos operem levando em conta as posições de Washington. Devese considerar que a constante turbulência política regional e a precariedade econômica tornam os países andinos bastante vulneráveis a influências externas. Os temas básicos da agenda política norte-americana pósguerra fria para a região andina giram em torno do narcotráfico, o antiterrorismo, a migração e o comércio exterior.

Mas também devemos observar que de modo algum as relações de amizade e inimizade entre os países latinos se encontram subsumidas na relação destes com os Estados Unidos enquanto potência continental, de modo que a
Mural Internacional

V. 7 | N. 2

JUL-DEZ 2016

dinâmica das relações entre os países latino-americanos serve de substrato para a emergência de iniciativas autônomas de cooperação e integração regional, bem como para a ocorrência de focos de tensão e eventuais conflitos armados (Domínguez 2003, p.25).

Na Guerra do Cenepa, vários interesses norte-americanos estavam em pauta: a validade dos acordos internacionais firmados, a resolução pacifica do conflito para evitar qualquer forma de contágio para outras regiões, a cooperação de uma região chave para a política de combate ao narcotráfico, o controle de proliferação de armas e a busca de livre comércio na região.

As relações bilaterais entre Estados Unidos e Equador eram de cooperação na área militar em especial em temas como educação e gestão. Por outro lado, as relações entre Estados Unidos e Peru eram de tensão tendo em vista vários fatores: disputadas em torno da pesca marítima, combate ao narcotráfico, a resiliência do Sendero Luminoso e o autogolpe realizado por Alberto Fujimori (Marcella 1995, pp.22-25)

Não obstante, no caso específico dos Estados Unidos, Aguilar (2013, pp.2223; pp.30-31) alega que a agenda externa norte-americana não coloca a América Latina como item prioritário, o que ao longo das últimas décadas 
permitiu uma ascendência brasileira, assumindo o Itamaraty um papel de liderança regional na proposição e articulação de ações no campo da segurança como o Conselho de Defesa Sul-americano (CDS). Contudo, mais do que a imposição de suas diretivas, o que a chancelaria brasileira tem buscado é a estabilidade da ordem regional.

Seguindo a lógica de funcionamento de um complexo de segurança, há de se registrar que transformações internas ou externas também são passíveis de ocorrer como parte do processo de acomodação residual da própria estrutura do sistema interamericano. Mas o destaque cabe, como já foi dito anteriormente, ao fato de que o complexo latino-americano combina overlay pela onipresença da hegemonia norte-americana com dinâmicas próprias de cooperação e disputa por poder.

Neste sentido, Aguilar (2013, pp.22-23) informa que em 2002 a Comunidade Andina das Nações (CAN) endossou o Compromisso de Lima - Carta Andina para a Paz e a Segurança, documento no qual os países da região afirmam a intenção de criar uma política comunitária de segurança cujas diretrizes seriam o estabelecimento de uma zona permanente de paz e a limitação os gastos militares. Esses documentos viriam a ser rediscutidos em 2010, levando à criação de princípios norteadores e de uma agenda estratégica no sentido de dar efetividade aos termos dos compromissos assinados.

Battaglino (2012, p.135) entende que a região andina não se enquadra na noção de comunidade de segurança ou zona de paz tendo em vista a reincidência de disputadas fronteiriças e rupturas diplomáticas. Mas tampouco se pode subestimar o impacto da democracia e do crescimento econômico na provisão de estabilidade nas relações regionais.

Na mesma ótica, Fuccille e Rezende (2013, p.83) argumentam que o subcomplexo de segurança norte-andino constitui um ambiente regional conflituoso devido a demandas fronteiriças, rivalidades culturais, instabilidades das instituições democráticas e a sobreposição norteamericana. Como é comum em caso de relações de rivalidade, no Equador se alimentou a memória coletiva do Peru como um adversário de natureza expansionista e dotado de uma aristocracia belicosa. Segundo Espinosa (1999, p.119) a região na qual se insere o Cenepa é percebido pelo Equador não apenas como um extrato da natureza, mas também como um espaço de sua soberania. 


\section{Muralf}

INTERNACIONAL
Mural Internacional

V. 7 | N. 2

JUL-DEZ 2016
Passemos agora ao nosso segundo ponto, qual seja, a análise das relações de paz e guerra entre Peru e Equador. De acordo com a versão peruana da colonização da região amazônica, foi primeiro Francisco de Orellana quem descobriu o Rio Amazonas em 1542, em uma expedição que partiu de Cuzco. Já segundo a versão equatoriana, várias expedições partiram de Quito e Guayaquil logrando chegar à Amazônia entre 1538 e 1541, resultando no estabelecimento de postos administrativos de Quito naquela região. Supostamente Orellana teria partido de Quito, e não de Cuzco, para alcançar o Rio Amazonas e o navegar até a sua foz no Oceano Atlântico (Lara 1994, pp.187-196). Porém, a despeito das respectivas versões, cabe lembrar que na época da descoberta do Rio Amazonas, tanto Cuzco quanto Quito faziam parte do Vice-Reino do Peru. Além disso, ambas as cidades estavam sob a tutela colonial espanhola.

Por outro lado, Osvaldo Hurtado (1981, pp.37-38) nos informa que não foi a Coroa espanhola que organizou e financiou a conquista do 'Reino de Quito', mas sim conquistadores particulares que para tanto criaram empresas privadas. Essas empresas foram responsáveis pela obtenção de créditos, receita financeira, recrutamento de pessoal e organização das expedições. Somente Francisco Pizarro teria recebido do Imperador da Espanha, Carlos V, uma autorização favorável à sua iniciativa.

De acordo com Iturralde e Franchi (2016, p.105) desde 1830, ano da independência do Equador, houveram ao menos 15 incidentes e 6 confrontos de natureza militar entre este país e o Peru. A principal área de disputa é na região amazônica tendo em vista seu valor econômico e a dificuldade de acesso e demarcação. Nesse período os diplomas legais firmados com o tempo foram rompidos. Os conflitos foram agravados por uma cultura de hostilidades e uma memória coletiva de ressentimento.

A região na confluência entre a fronteira entre os países na base aquífera que dá acesso ao Amazonas tem sido objeto de ativo interesse por ambos os lados. As principais ocorrências armadas entre os dois países tiveram início em 1941, quando um ataque peruano foi deflagrado contra o Equador que resultou na vitória do primeiro, o que significou um grande triunfo político para o então presidente peruano Manuel Prado, permitindo, assim, a recuperação do prestígio das forças armadas daquele país depois de uma derrota frente ao Chile. No Equador a derrota gerou um sentimento de revanche. 
Embora partilhando a herança comum do Império Espanhol nas Américas, Peru e Equador constituíram parte significativa de sua identidade na oposição mútua que se expressa no plano discursivo, mas também geopolítico e territorial. Na Guerra de Zarumilla de 1941 as tropas peruanas comandadas pelo General Eloy Ureta invadiram o Equador e tentaram forçar a demarcação das fronteiras com base nos interesses nacionais do Peru (Marcella 1995, pp.5-6). Na ocasião, o Peru se preparou para o conflito e se aproveitou de um momento conturbado da vida política do vizinho para tentar impor, pela força, sua vontade geopolítica (Cotler 1985, pp.242-243). Desde aquele momento, o contencioso na região amazônica tem tido um relevante papel na construção da identidade nacional de ambos os lados, mas especialmente no Equador, cujo militarismo alimentou um sentimento de revanche contra os vizinhos do sul.

A ocupação peruana de parte do território equatoriano levou à assinatura do Protocolo do Rio de 1942, que foi elaborado sob comando brasileiro com suporte técnico norte-americano. Aquele protocolo pretendia pôr fim aos conflitos, mas, devido a uma falha cartográfica e a insatisfação equatoriana com os termos do acordo, ele terminou sendo refutado de maneira unilateral pelo governo de Quito, alegando também que ele havia sido assinado sob coerção uma vez que seu território fronteiriço havia sido ocupado.

Novamente os dois países viriam a se enfrentar no Incidente de Paquisha, no qual o Peru tentou impor, pela força, a implementação dos termos finais do Protocolo do Rio. Apesar da vitória, o governo peruano não obteve seu intento e, depois de 14 anos de preparativos, o Equador, enfim, conseguiu enfrentar e vencer as forças peruanas na Guerra do Cenepa em 1995. Porém a limitada vitória equatoriana e o risco de uma retaliação peruana levaram o Equador a aceitar negociar a linha de fronteira com base nos termos acordados em 1942 .

Em suma, devido à constatação de ambos os lados, da existência de uma balança de poder bilateral, eles se viram compelidos a negociar a paz, de modo que ambos obtiveram parte de seus interesses, com o Peru confirmando a maioria dos termos previamente acordados e o Equador obtendo acesso ao complexo hidrográfico da bacia amazônica. De acordo com Ojeda (2015, pp.228-229) o conflito em Cenepa se desenvolveu de forma ativa tanto no plano tático, quando as hostilidades se iniciaram na região da Base Norte (Equador), quanto no plano 


\section{Muralf}

INTERNACIONAL

diplomático, em função das negociações para o desenlace da querela.

Do ponto de vista estratégico, na Guerra do Cenepa, o Peru empregou caças Su-22, Mirage 5, A-37, Canberra e helicópteros Mi 8TV HipC, enquanto o Equador privilegiou o uso de caças Kfir, Mirage F1 e A-37. Ao contrário dos confrontos precedentes, nesta ocasião o desempenho de pilotos e aeronaves equatorianos se mostrou superior ao de seu adversário. $\mathrm{O}$ resultado foi uma vitória do Equador na batalha aérea, que mostrou ao Peru que uma nova investida armada seria prontamente respondida (Nogueira e Herz 2001, s/p).

Do ponto de vista diplomático, durante os três anos e meio pós Guerra do Cenepa em que ambos os governos se engajaram em permanentes negociações para construir uma saída pacífica para a disputa de fronteira, o governo peruano terminou reconhecendo a existência de um problema na delimitação do seu território na fronteira com o Equador, fato este que era anteriormente negado, mas que agora, depois do êxito militar equatoriano, o governo de Lima se viu obrigado a admitir e incluir na pauta de negociações bilaterais.

A questão territorial em si era de menor monta visto que não havia grande área em demanda, mas sim a demarcação
Mural Internacional

V. 7 | N. 2

JUL-DEZ 2016

fronteiriça pendente. Podemos caracterizar o conflito como uma guerra pelo enfrentamento de tropas oficiais, choque físico entre as forças e a busca pela consolidação dos limites nacionais. Ajunta-se a isso ama busca tardia pela consolidação do Estado Nação, com seu povo, governo e território.

Visto de outro ângulo, a limitada vitória equatoriana e o risco de uma retaliação peruana levaram o Equador a aceitar negociar a linha de fronteira com base nos termos acordados em 1942. Devido à constatação de ambos os lados, da existência de uma balança de poder bilateral, eles se viram compelidos a negociar a paz, de modo que ambos obtiveram parte de seus interesses, com o Peru confirmando os termos previamente acordados, e o Equador obtendo acesso ao complexo hidrográfico da bacia amazônica.

$\mathrm{Na}$ época do conflito de 1995, o Peru vivia um conturbado processo de eleição presidencial. $\mathrm{O}$ presidente Fujimori se encontrava em uma delicada situação, pois não podia mobilizar o conflito para aumentar seu poder político sob o risco de fortalecer os militares que ele mesmo havia afastado do poder. Para agravar, autoridades militares e civis estavam às voltas com acusações de envolvimento com o narcotráfico. Além disso, as forças de 
defesa peruanas já se encontravam mobilizadas na luta interna contra os grupos guerrilheiros de orientação maoísta. Sob risco de perder nas duas frentes, ao que parece, Fujimori decidiu priorizar a luta interna. Assim, tomando a dicotomia Estado fracolforte como conjuntural, podemos dizer que o Equador se favoreceu de um quadro de fragilidade interna do seu rival histórico.

Os resultados para a dinâmica doméstica de cada país foram um incremento no prestígio dos militares no Equador, com a reafirmação dos privilégios econômicos destes, e uma dura crítica de setores civis e militares ao governo de Alberto Fujimori no Peru. No jogo diplomático, a chancelaria equatoriana se mostrou mais agressiva, procurando obter apoio regional para sua causa e assim reduzir a vantagem militar peruana. Enquanto isso, o governo peruano se isolou de seus pares na região. Os principais fatores que contribuíram para a assinatura do tratado de paz que colocou fim ao conflito foram o desgaste político, especialmente do Peru, os gastos econômicos de ambos os lados, o repúdio da sociedade civil dos dois lados da fronteira e a ativa pressão externa de Estados Unidos e também Brasil.
Podemos agora discutir nosso terceiro ponto, que consiste na Missão de Observadores Militares

Equador/Peru (MOMEP) e a atuação do Brasil. Nas últimas décadas a chancelaria brasileira tem atuado no sentido de projetar o Brasil como agente de relevo na construção e manutenção da segurança internacional, seja liderando iniciativas de integração como o Mercosul e a Unasul, seja atuando em missões de paz como no Haiti ou comandando operações militares como a Missão de Observadores Militares Equador/Peru (MOMEP) na fronteira entre Peru e Equador (Ludwig 2015, pp.35; 151-153)

Podemos elencar os fatores que permitiram ao Brasil um papel mais ativo no Complexo de Segurança Sulamericano: a posição geográfica do Brasil facilita a logística de operações em todo o subcontinente e permite ao mesmo funcionar como ele de ligação entre a região Andina e o Cone Sul; alguns itens da agenda de segurança do Brasil são compartilhados com os demais países da região, como o citado narcotráfico e também o crime organizado transnacional; ademais o Brasil detém o maior investimento bruto em Forças Armadas na América do Sul. Mas cabe destacar que o Brasil, embora detenha o maior PIB da região sendo uma das maiores economias mundiais, 


\section{Muralf}

INTERNACIONAL

ainda reluta em se engajar de forma ativa em itens da agenda externa andina como o combate sistêmico ao narcotráfico e o narcoterrorismo (Rebello 2013, pp.110-111).

Conforme podemos verificar no quadro 1 a seguir, no período compreendido entre 1995 (ano da Guerra do Cenepa) e 2015 os gastos militares na América do Sul foram liderados amplamente pelo Brasil, com gastos estimados em US\$ 24.618,00 bilhões, o que o credencia como liderança regional. Contudo, para fins de comparação tendo em vista a tese da liderança brasileira combinada
Mural Internacional

V. 7 | N. 2

JUL-DEZ 2016 com o overlay norte-americano, foram incluídos os gastos militares dos Estados Unidos. Pode-se perceber a enorme discrepância tendo em vista que os Estados Unidos despendem mais em assuntos militares que a soma de todos os países do complexo sul-americano, tendo atingido em 2015 a cifra de US\$ $596.010,00$ bilhões. A rigor o gasto militar sul-americano agregado para o ano de 2015 não chegou a 10\% do montante empregado pelos Estados Unidos.

\section{Quadro 1. Gastos militares por países selecionados, em bilhões de US\$ (1995- 2015 - ano/valor de referência: 2016)}

Dados em US\$, a preços correntes, convertidos à taxa do ano de 2016

Dados em azul são estimativas, em vermelho altamente incertos.

\begin{tabular}{|l|l|l|l|l|l|}
\hline País & $\mathbf{1 9 9 5}$ & $\mathbf{2 0 0 0}$ & $\mathbf{2 0 0 5}$ & $\mathbf{2 0 1 0}$ & $\mathbf{2 0 1 5}$ \\
\hline EUA & 278.856 & 301.697 & 503.353 & 698.180 & 596.010 \\
\hline Argentina & 3.802 & 3.267 & 1.700 & 3.475 & 5.483 \\
\hline Bolívia & 141 & 173 & 169 & 327 & 576 \\
\hline Brasil & 14.319 & 11.344 & 13.589 & 34.003 & 24.618 \\
\hline Chile & 1.828 & 2.103 & 3.100 & 4.894 & 4.637 \\
\hline Colômbia & 2.619 & 3.028 & 4.914 & 10.422 & 9.127 \\
\hline
\end{tabular}




\begin{tabular}{|l|l|l|l|l|l|}
\hline Equador & 475 & 266 & 954 & 2.094 & 2.449 \\
\hline Guiana & 5.7 & 12.6 & 18.5 & 31.1 & 46.4 \\
\hline Paraguai & 207 & 110 & 77.5 & 205 & 387 \\
\hline Peru & 1.413 & 912 & 1.149 & 1.956 & 3.191 \\
\hline Uruguai & 524 & 556 & 347 & 756 & 970 \\
\hline Venezuela & 1.199 & 1.788 & 2.054 & 3.363 & 5.265 \\
\hline
\end{tabular}

Fonte: SIPRI, 2017. www.sipri.org

$\mathrm{Na}$ análise de Ojeda (2015, p.232) a MOMEP, derivada da Declaração de Paz do Itamaraty e atuando nos marcos desse diploma legal, pode ser descrita como uma missão de paz convencional que teve como tarefa supervisar o cessar fogo, desmobilizar as tropas de ambos os lados e criar uma área desmilitarizada.

De acordo com Kilroy Jr. (2009, p.16) e também Laban (2009, pp.196-197), se o plano tático-estratégico a MOMEP estava sob a orientação norte-americana, isso não impediu que os demais países envolvidos tivessem seus papéis. Ao Brasil coube o comando geral das atividades, o que lhe daria experiência para mais tarde assumir o comando da missão de paz da ONU no Haiti. A Argentina conseguiu aproveitar sua experiência no Cenepa para melhorar seu status pós-Malvinas/Falklands e ganhar experiência em missões de paz, atividade que o próprio Chile passou a considerar como uma das metas viáveis para suas forças armadas. $\mathrm{O}$ sucesso tático da MOMEP pode ser evidenciado pela capacidade de separar cerca de 5.000 militares na zona de conflito e desmobilizar mais de 140.000 das tropas de ambos os lados. No nível de análise global, por ocasião do conflito do Cenepa, sua relevância geopolítica era reduzida tendo em vista o baixo interesse da potência hegemônica na região e na concomitância da Guerra da Bósnia na qual os Estados Unidos se engajaram ativamente. A despeito disso o governo norte-americano delegou ao "U.S. Southern Command" (SOUTHCOM) a tarefa de dar suporte logístico e operacional através da "Operation Safe Border" à construção 


\section{Muralf}

INTERNACIONAL

da paz entre Peru e Equador, contanto com um efetivo limitado de 82 pessoas e com duração definida de um ano.

Iturralde e Franchi (2016, pp.110-111) afirmam que um fato relevante na atuação da MOMEP foi a incorporação de oficiais peruanos e equatorianos no processo de observação gerando um ambiente de confiança recíproca. Após da resolução do conflito pelo Tratado do Itamaraty de 1998 abriu-se uma agenda de cooperação entre os países, que inclui o combate ao narcotráfico e o narcoterrorismo, agenda defendida pelos Estados Unidos. Além disso se envidou esforços bilaterais para remover/desativar as cerca de $15 \mathrm{mil}$ minas terrestres disseminadas na fronteira.

Cabe observar no caso da Guerra do Cenepa que a escalada da crise que levou ao conflito interestatal foi controlada pela MOMEP enquanto mecanismo multilateral, mas sem gerar a partir dela uma institucionalidade responsiva acerca de tensões e conflitos na região (Teixeira Júnior 2012, p.198), ou seja, foi um instrumento pontual para um fim específico - uma espécie de força tarefa.

Então podemos dizer que as principais consequências do conflito de 1995 foram que o Equador conseguiu uma ligeira vantagem no conflito armado,
Mural Internacional

V. 7 | N. 2

JUL-DEZ 2016

mas com a possibilidade de rearmamento bilateral em aberto. Enquanto isso, de acordo com Biato (1999, pp.242-247) a operação de paz multinacional liderada por Brasil e EUA, a Missão de Observadores Militares Equador-Peru (MOMEP), ampliou a capacidade regional de resolução de conflitos com autonomia, rompendo com a tradição de resolver os conflitos através de arbitragem externa (Corte Internacional de Justiça, ONU, etc.). O Brasil colocou em evidência suas intenções de liderança regional, sem deixar de observar a supremacia norte-americana no Continente.

\section{Considerações finais}

Pelo exposto, pode-se argumentar que a relativa paz no subcontinente sulamericano é fruto de uma lógica de coerção local e internacional levada a cabo pelos Estados Unidos, num processo de overlay, bem como resultado de aprendizagem histórica dos países da região acerca dos custos da guerra e vantagens da cooperação (Ludwig 2015, p.28)

A Guerra do Cenepa entre Equador e Peru, além de outras peculiaridades, produziu três resultados básicos: ela apontou para a existência de uma balança de poder entre os dois países; não gerou nenhuma alteração substancial no conteúdo do tratado 
firmado previamente sobre a questão em disputa, a saber: a fronteira na base do Rio Cenepa; nem tampouco implicou em transferência de território. Então, como podemos explicar a dinâmica do conflito entre Peru e Equador?

A conclusão central da análise aqui empreendida é que, em primeiro lugar, um padrão recorrente de hostilidades favorece um comportamento ofensivo e, em segundo lugar, a certeza sobre a balança de poder favorece as negociações. Assim, a longa história de desavenças entre Peru e Equador tem favorecido o ataque mútuo, tal como gerou um incentivo para a ocorrência do conflito de 1995.

Mas a ligeira superioridade equatoriana no combate aéreo travado no conflito do Cenepa, aliada à vulnerabilidade do cenário interno peruano, permitiram a constituição de um equilíbrio entre os dois Estados que favoreceu a assinatura do tratado de paz sob o patrocínio de quatro países garantes, a saber: Estados Unidos, Brasil, Argentina e Chile. Dentre estes países, devemos destacar a relevância dos Estados Unidos para o processo de constituição da paz, devido à sua posição de potência hegemônica e sua capacidade de pressão sobre os governos latino-americanos.

Tendo isto em vista, como conclusão subjacente de análise, sugerimos que o sistema latino-americano combina uma dinâmica de segurança própria com o overlay norte-americano, isto quer dizer que, se a presença da hegemonia norteamericana não impede a ocorrência de conflitos devido a um padrão regional de segurança dotado de certo grau de autonomia, por outro lado ela é elemento destacado nos processos de resolução de conflitos e estabilização das pressões regionais.

O caso do conflito entre Peru e Equador no Cenepa indica que a hegemonia norte-americana não previne a ocorrência de conflitos, mas concorre para a resolução dos mesmos quando estes ocorrem. $\mathrm{O}$ fato é que, do ponto de vista estratégico, no âmbito do Complexo de Segurança Sul-americano, qualquer pretensão de um Estado em agir em prol da manutenção ou alteração de seu status quo regional deve levar em conta a posição norte-americana e, também, a possibilidade de intervenção do mesmo ao longo de um conflito. Neste sentido a postura diplomática adotada pelo Brasil se mostrou adequada tendo em vista seus interesses estratégicos e limites de ação para, ao mesmo tempo, satisfazer sua condição de liderança regional e evitar um confronto com a presença norteamericana. 


\section{Muralf}

INTERNACIONAL

Mural Internacional

V. 7 |N. 2

JUL-DEZ 2016

\section{Bibliografia}

Aguilar, S.L.C. (2013). "Segurança na américa latina: cenários e perspectivas. Monções". Revista de Relações Internacionais da UFGD, Dourados, v.2. n.3, jan./jun. [online]. Disponível em: http://ojs.ufgd.edu.br/index.php/moncoes/article/view/2529/1537 [acesso em junho de 2017]

Battaglino, J. M. (2012). “A coexistência entre paz e conflito na América do Sul: em direção a uma nova conceituação dos tipos de paz”. Rev. Bras. Polít. Int. 55 (2): 131151. [online]. Disponível em: http://dx.doi.org/10.1590/S0034-73292012000200008 [acesso em junho de 2017]

Biato, M. F. (1999). "O processo de paz Peru-Equador”. Parcerias Estratégicas, vol. $\mathrm{n}^{\circ}$ 6, março. [online] Disponível em: http://seer.cgee.org.br/index.php/parcerias_estrategicas/article/viewFile/62/54 [acesso em julho de 2016]

Bonilla, A. et alli. (2002). Orfeo en el infierno: una agenda de política exterior ecuatoriana. FLACSO Ecuador, Quito.

Buzan, B. (1991). Peoples, states and fear: an agenda for international security studies in the post-cold war era. Boulder, Colorado: Lynne Rienner Publishers.

Buzan, B.; Jones, C.; Little, R. (1993). The logic of anarchy. New York: Columbia University Press.

Buzan, B.; Waever, O. (2003). Regions and Powers: the structure of international security. Cambridge: Cambridge University Press.

Cotler, J. (1985). Clases, estado y nación en el Perú. Lima: Instituto de Estudios Peruanos.

Domínguez, J. I. et alli (2003). Conflictos territoriales y democracia en América Latina. Buenos Aires: Siglo XXI Editores Argentina, Universidade Belgrano, Flacso. 
Espinosa, C. (1999). 'La negociacion como terapia: memoria, identidad y honor nacional en el proceso de paz Ecuador-Peru', in: Ecuador - Peru: Horizontes de la negociación y el conflito. Adrian Bonilla (Editor). Quito: FLACSO Ecuador.

Ferraz, D. A.; Hauser, D. (2002). A nova ordem mundial e os conflitos armados. Belo Horizonte: Mandamentos.

Fuccille, A.; Rezende, L. P. (2013). "Complexo regional de segurança da América do Sul: uma nova perspectiva". Contexto int., Jun, vol.35, no.1, p.77-104. [online]. Disponível em: http://dx.doi.org/10.1590/S0102-85292013000100003 [acesso em junho 2017]

Hurtado, O. (1981). O poder político no Equador. Trad. Raul do Valle. Rio de Janeiro: Paz e Terra.

Iturralde, M.; Franchi, T. (2016). "El conflicto del Cenepa: los dividendos de la paz". Military Review, Cuarto Trimestre, pp. 104-112. [online]. Disponível em: http://www.armyupress.army.mil/Portals/7/military-

$\underline{\text { review/Archives/Spanish/MilitaryReview_20161231_art016SPA.pdf }}$ [acesso em junho 2017]

Kilroy JR., R. J. (2009). "Guaranteeing Peace in Latin America: A Case Study in Conflict Resolution Involving the Peru and Ecuador Border Dispute of 1995", in: International Political Science Association Meeting, Department of International Studies, Virginia Military Institute, Santiago, Chile, July 12-16. [online]. Disponível em: http://paperroom.ipsa.org/papers/paper_790.pdf. [acesso em junho de 2017]

Laban, P. L. (2009). "El conflito territorial entre Ecuador y Perú por el Río del Cenepa (1995): entre una mediación falida y outra exitosa". Revista Pléyade, n. 4, segundo semestre. [online]. Disponível em: https://dialnet.unirioja.es/servlet/articulo?codigo $=3154692$. [acesso em junho de 2017]

Lara, J. S. (1994). Breve historia contemporánea del Ecuador. Cidade do México: Fondo de Cultura Económica.

Ludwig, F. J. (2015). A Arquitetura de Paz na América do Sul: a projeção regional e internacional do Brasil na consolidação da paz. Tese de Doutorado em Relações Internacionais, 257fls. Universidade de Coimbra, Coimbra. 


\section{Muralf}

INTERNACIONAL

Mural Internacional

V. $7 \mid$ N. 2

JUL-DEZ 2016

Marcella, G. (1995). "War and peace in the amazon: strategic implications for the united states and latin américa of the 1995 Ecuador-Peru War". Department of national security and strategy. November 24. [online]. Disponível em: http://ssi.armywarcollege.edu/pdffiles/00037.pdf. [acesso em julho de 2016]

Nogueira, J. P.; Herz, M. (2001). "O Processo de Mediação do Conflito entre o Peru e o Equador", in: XXV Encontro da ANPOCS. Seminário Temático: A Inserção Internacional do Brasil: Balanço dos Anos 90 e Perspectivas Futuras. Caxambu, outubro. [online]; Disponível em: http://www.anpocs.org.br [acesso em julho de 2016].

(2002). "Ecuador vs. Peru: peacemaking amid rivalry". International Peace Academy Occasional Paper Series. Boulder, Colorado: Lynne Rienner Publishers.

Núñez, J. R. (2002). "A 21st century security architecture for the americas: multilateral cooperation, liberal peace and soft power". Foreign Affairs. August. [online]. Disponível em: https://www.foreignaffairs.com/reviews/capsulereview/2003-01-01/21st-century-security-architecture-americas-multilateral. [acesso em julho de 2016].

Ojeda, C. D. V. (2015). "El Conflicto del Cenepa: su camino hacia la paz". Conjuntura Global, Vol. 4, n. 2, maio/ago., p. 221-235. [online]. Disponível em: http://www.humanas.ufpr.br/portal/conjunturaglobal/files/2016/02/9-El-ConflictoDel-Cenepa-Su-Camino-Hacia-La-Paz.pdf. [acesso em julho de 2017]

Rebello, L. F. (2013). Segurança e defesa regional: a inserção brasileira na subregião Andino Amazônica. Dissertação de Mestrado em Relações Internacionais, 152fls. UFSC, Florianópolis.

Teixeira Júnior, A.W.M. (2012). "Agendas e dinâmicas de segurança andina e o conselho de defesa sul-americano", in Oliveira, RP.; Nogueira, SG.; Melo, FR., orgs. América Andina: integração regional, segurança e outros olhares. [online]. Campina Grande: EDUEPB, pp. 191-209. Disponível em: http://books.scielo.org/id/7wnmw/pdf/oliveira-9788578791858-10.pdf. [acesso em julho de 2017]. 


\section{8}

Waltz, K. N. (1959). Man, state and war: a theoretical analysis. New York: Columbia University Press. 